\title{
Violencia y solidaridad en Pastel de Lagrange de Juan Mayorga
}

\section{Mónica Molanes Rial}

\section{(2) OpenEdition}

1 Journals

\section{Edición electrónica}

URL: https://journals.openedition.org/cher/1863

DOI: $10.4000 /$ cher. 1863

ISSN: 2803-5992

\section{Editor}

Presses universitaires de Strasbourg

\section{Edición impresa}

Fecha de publicación: 1 diciembre 2017

Paginación: 167-173

ISBN: 978-2-86820-962-7

ISSN: 1968-035X

\section{Referencia electrónica}

Mónica Molanes Rial, «Violencia y solidaridad en Pastel de Lagrange de Juan Mayorga», reCHERches [En línea], 19 | 2017, Publicado el 01 diciembre 2021, consultado el 04 febrero 2022. URL: http:// journals.openedition.org/cher/1863 ; DOI: https://doi.org/10.4000/cher.1863

\section{(c) (i) (ㅇ)}

Ce(tte) œuvre est mise à disposition selon les termes de la Licence Creative Commons Attribution Pas d'Utilisation Commerciale - Partage dans les Mêmes Conditions 4.0 International. 


\title{
Violencia y solidaridad en Pastel de Lagrange de Juan Mayorga
}

\author{
MÓNICA MOLANES RIAL ${ }^{1}$
}

a «indagación acerca de la violencia» es el gran tema del teatro de Juan
Mayorga: Yo creo que hay un tema que vertebra mi obra. Es la indagación acerca de la violencia. La violencia es un tema que me preocupa mucho y que está en alguna medida en todos mis textos. Entiendo por violencia la dominación de uno sobre otro o de una realidad sobre un ser humano, sea hombre o mujer. Me interesa poco la violencia explícita, o sea, física. Esa no creo que merezca la pena ser presentada en escena porque es evidente, es obvia. (Gabriele 2000: 1097)

Entendida en sentido amplio, opera en el conjunto de su obra como germen del conflicto dramático. La vertiente de teatro histórico-crítico que aglutina buena parte de la producción dramática de Mayorga alude a algunos de los conflictos bélicos y regímenes autoritarios que constituyen la historia europea del siglo veinte. La dramatización de estos asuntos lleva ya implícita la evocación de contextos de violencia en obras como Cartas de amor a Stalin, Himmelweg o El cartógrafo, cuyas tramas se sitúan en los años de la dictadura estalinista o del genocidio nazi. Aun así, el foco de atención no recae tanto sobre los crímenes de guerra como sobre la mostración de situaciones concretas en las que se dan actitudes o comportamientos violentos de manera más velada. El interés por el desvelamiento de los diversos modos en los que se ejerce la violencia figura en buena parte de las obras de Mayorga en las que se dirimen asuntos políticos y sociales de profundo calado, como la pederastia en Hamelin o la xenofobia en Animales nocturnos. En piezas como estas, la opresión, la coacción o la manipulación encubiertas de un individuo sobre otro en el ámbito de lo cotidiano se presentan como asuntos centrales. El diseño de dos personajes

1 Doctoranda, Universidade Vigo. Actualmente trabaja en el Instituto del Teatro de la Universidad Complutense de Madrid como contratada en el proyecto de investigación TEAMAD. 
enfrentados -cara y envés del mismo- tan característico de la construcción dramatúrgica mayorguiana está al servicio de estos conflictos.

Son las maneras más sutiles de ejercer la violencia las que aparecen con mayor frecuencia. De entre ellas, destaca de modo especial el uso de la palabra con tal fin, pues no son pocas las piezas en las que el lenguaje funciona como medio instrumental de coerción, abuso o imposición: en El traductor de Blumemberg se destaca su poder como transmisora del mal en el ejercicio de la traducción. Por el contrario, la mostración de violencia física encuentra escaso acomodo en la obra de Mayorga, salvo en textos como Amarillo, donde la palabra se hace símbolo de un mal recuerdo cuya pronunciación en voz alta es contestada con una agresión; es esta una de las escasas piezas breves en las que hay violencia explícita en escena. La otra, BRGS, cuyos personajes terminan golpeándose, apunta hacia la paradójica inutilidad de la palabra como resolución a un conflicto entre dos lectores.

En esa misma línea se sitúa la última pieza breve escrita por Juan Mayorga. Pastel de Lagrange surge de una experiencia de La Corsetería, espacio de trabajo y laboratorio experimental de creación teatral dirigido por Sanchis Sinisterra en Madrid. El objetivo de la propuesta era tratar de acercar el mundo de la ciencia al del teatro. Mayorga escribe Pastel de Lagrange, bajo premisa de tratar el asunto de los mundos paralelos. El texto sirve como escena inicial a partir de la que surgen nuevos desarrollos. Se hace mediante un proceso de creación de escritura colectiva por parte de un equipo de dramaturgos del Nuevo Teatro Fronterizo, coordinados por Sanchis Sinisterra, a partir de conversaciones con cosmólogos del CSIC. El resultado es la obra Multiversos, de la que se hizo una lectura dramatizada en el marco de las $V$ Jornadas de Teatro Científico Divulgativo, Ciencia y Teatro 2013 en Mérida y Medellín, a cargo de Quiqué y Yeray Bazo, Eva Redondo, Sanchis Sinisterra y Enrique Torres, con dirección de Daniel Erice. También la compañía Teatro para Armar hizo una lectura dramatizada en Madrid el 15 de marzo de 2015, cuyo trabajo sobre el texto incluye la elaboración de una guía didáctica para el alumnado de secundaria de los institutos de Madrid.

\section{Ciencia y violencia, cultura y barbarie}

La relación entre ciencia y teatro no es extraña a la historia de la literatura dramática: baste recordar, de modo muy general, los primeros intentos de Louis Figuier por crear el género de théâtre scientifique en el siglo XIX, su auge en el siglo xx debido a las consecuencias dramáticas de la bomba atómica con obras como La vida de Galileo de Brecht o Los Físicos de Dürrenmatt y su continuación hasta finales del siglo xx, con textos como Arcadia de Tom Stoppard. En España, en los últimos años, el interés del teatro por la ciencia no ha sido menor, en especial en lo relativo al campo de la física, tal y como ya señalaba Yolanda Pallín en el año 2009: «el azar y la necesidad, la teoría del caos, la física cuántica, la autosimilitud, la incertidumbre, la ruptura de la lógica newtoniana... aparecen 
de forma natural en la mayoría de los seminarios de escritura teatral, junto con la crisis de la representación» (Surbezy en prensa) ${ }^{2}$.

Precisamente a esa línea de creación dramática sobre física cuántica se puede adscribir Pastel de Lagrange ${ }^{3}$, encargo particular de Sanchis Sinisterra, quien ya había escrito sobre dicha disciplina en Perdida en los Apalaches, juguete cuántico. La vinculación entre teatro y ciencia no es ajena al trabajo dramático y ensayístico de Juan Mayorga. Su propia formación académica e intelectual, que combina Matemática y Filosofía, caracteriza su obra teatral. Los números imaginarios en El chico de la última fila y los estudios cartográficos en El Cartógrafo han servido de resortes dramáticos para expresar los peligrosos límites de la imaginación o de la censura. En este caso, la anécdota argumental de Pastel de Lagrange es la siguiente: Samuel y Toñi se presentan en casa de María José. Está preparando un pastel siguiendo las indicaciones de un programa televisivo sobre divulgación científica en el que un matemático francés explica la teoría de los universos múltiples, discurso en el que repite con frecuencia el apellido «Lagrange». Samuel se disculpa por la visita inesperada que justifica con la repentina decisión de Toñi. Tras preguntar María José a Toñi por su experiencia y habilidad, se descubre que lo que esta viene a comprar es una pistola para matar a su marido. El arranque de la obra, según palabras del propio autor ${ }^{4}$, es una foto que vio en prensa hace algunos años. En ella, se apreciaba a un grupo de mujeres reunidas en el interior de una casa que estaban contemplando un estuche. Mayorga cuenta que la imagen le recordó a aquellas mujeres que ofrecían venta de productos a domicilio, como los de cosmética Avon; o a aquellas señoras que organizaban en su propia casa la venta de robots de cocina o de aspiradoras. Pero lo que en realidad vendían las mujeres de la foto eran armas ${ }^{5}$.

Según se indica en las acotaciones de la pieza, del discurso científico divulgativo del matemático francés sobre la teoría de los universos múltiples que María José está viendo en la televisión se destaca el apellido «Lagrange», que además da título a la pieza. Joseph-Louis Lagrange, matemático italo-francés nacido en 1736, es uno de los científicos más reconocidos del siglo XVIII por sus

2 Entre el 15 y el 16 mayo de ese año 2009, se celebró en la Université Toulouse-Le Mirail un coloquio titulado Universcènes, el teatro cuántico que reunió a dramaturgos y especialistas en estudios teatrales del ámbito francés y español.

3 El texto permanece inédito hasta el momento, por lo que las referencias que se hacen a lo largo de este trabajo pertenecen al texto que forma parte del archivo del autor.

4 Las declaraciones pertenecen a una entrevista realizada a Juan Mayorga, cuya práctica totalidad se ha publicado en el número 823-824 de la revista Insula en el verano de 2015, monográfico dedicado al estudio de la dramaturgia española actual coordinado por Anxo Abuín.

5 La escritura de textos dramáticos a partir de material fotográfico, fílmico o periodístico es práctica habitual en el quehacer dramático de Juan Mayorga: La biblioteca del diablo surgió de la lectura de un artículo de prensa sobre exilio y repatriación (Molanes 2011); Himmelweg fue escrito después de que asistiese a una conferencia sobre Claude Lanzmann (Aznar Soler 2011: 24); La mano izquierda fue creado a partir de una fotografía de Sebastião Salgado. 
múltiples trabajos en los campos de la matemática, la física o la astronomía. En esta última disciplina, «realizó estudios de dinámica de los cuerpos del Sistema Solar [...] Entre sus descubrimientos astronómicos es notable el de los llamados puntos de liberación de un cuerpo celeste, conocidos como los Puntos de Lagrange, que tienen importantes aplicaciones astronáuticas» ${ }^{6}$. Estos puntos han sido escenario de no pocas obras de ciencia ficción en las que se han propuesto como posibles lugares para habitar mundos paralelos ${ }^{7}$.

Con la referencia a Lagrange y al discurso divulgativo del matemático francés, Mayorga engarza la teoría del multiuniverso en el engranaje dramático como elemento de extrañamiento al vincularla a la elaboración del pastel. Quizá pueda resultar útil para explicar la conexión entre ambos elementos volver al trabajo que Juan Mayorga publicó en 2010 titulado Elipses de Benjamin. En él sugiere emplear la imagen de la elipse -muy próxima a la definición que de concepto daban los clásicos ${ }^{8}$ - para leer a Benjamin tal y como el autor alemán hace con la obra de Kafka:

Quien con frecuencia desencadena su pensar al descubrir la conexión -que nunca es identificación, sino vínculo atravesado de tensiones- de dos motivos distantes que al asociarse abren un campo de preguntas. [...] Lo decisivo es que ninguno de los objetos sea luego pensado sin atender al otro y que el vínculo entre ambos haga aparecer un lugar que ninguno de ellos crearía por sí solo. Ese espacio será tanto más rico cuanto más distantes y heterogéneos los términos del par, cuanto menos afines parezcan en principio, cuanto más imprevisto su encuentro [...] Ese espacio puede ser llamado imagen dialéctica, que no es el vínculo de dos objetos distantes, sino el lugar tenso y denso creado por un emparejamiento improbable. (Mayorga 2010: 373)

Es precisamente «un emparejamiento improbable» el que da título a la pieza: «pastel» $y$ «Lagrange». El binomio funciona como marco estructural, ya que abre y cierra la pieza, y como leitmotiv a lo largo de la obra, pues hay una alusión discontinua aunque constante por parte de María José a los pasos que debe seguir para hacer la receta según la explicación del matemático francés. Son dos objetos distantes: el pastel, la construcción de un placer; el asesinato, la

6 http://www.astromia.com/biografias/lagrange.htm

7 Borges, uno de los escritores que más ha influido en la poética dramática de Juan Mayorga, se adelantó a los trabajos fundacionales de Everett sobre la teoría de los mundos paralelos. El narrador argentino, que ya había colaborado en la revista Sur dirigida por Victoria Ocampo en Buenos Aires en los años treinta que desarrolló un nuevo enfoque sobre la literatura fantastique, incluyó en su cuento El jardín de los senderos que se bifurcan publicado en 1941 una explicación llamativamente similar a la interpretación de los universos paralelos que dio a conocer Everett dieciséis años después, en 1957. Alfonso Rojo lo explica en su artículo «El jardín de los mundos que se ramifican: Borges y la mecánica cuántica» publicado en la revista Ciberletras: Revista de crítica literaria y de cultura, 1, 1999.

8 Gracián, en Agudeza y arte de ingenio, define brevemente el término de este modo: «Es un acto de entendimiento que exprime la correspondencia que se halla entre los objectos». 
destrucción y el horror. Y en medio, la cita a Lagrange, la tradición humanista, la cultura, el pozo del conocimiento científico del hombre, transmutado en elemento fantástico nada habitual -a excepción de los animales parlantes- en el teatro de Mayorga. El resultado de la receta que María José elabora a partir del discurso del matemático es un pastel en forma de corazón, icono del amor por antonomasia en nuestro imaginario colectivo que resulta especialmente significativo en el contexto de esta obra, pues hay una relación matrimonial que se expone como germen del conflicto. Como se indica en la última acotación del texto, el pastel es cortado en tres trozos que, aun humeantes, los tres personajes «se meten enteros en la boca». La voracidad y obscenidad que desprende la imagen refuerza la construcción de ese ambiente de inquietante violencia, que resulta incluso más perverso con guiños irónicos como la advertencia de María José a Toñi a propósito del precio de la pistola: «lo barato sale caro». Esa perversidad en el contexto de la amabilidad del hogar recuerda sobremanera a la escena del bar de otra pieza breve, El buen vecino, donde, en un ambiente inicial de confianza, la simple invocación de la ley de extranjería y el gesto de un brindis condenan al emigrante a plegarse al servicio de su vecino de arriba.

La incidencia en la conjugación del discurso científico y la acción violenta alcanza su grado más simbólico en la presentación del muestrario de pistolas que María José enseña a Toñi: una «Gauss» de ochenta y nueve milímetros, con la que apunta al matemático de la tele, y una «Heidegger» de mango blanco que dispara cartuchos «Jünger». El juego onomástico es rasgo característico del teatro de Mayorga que, en este contexto, parece subrayar la idea de la contraposición entre cultura y barbarie, de matriz benjaminiana, tan recurrente en sus textos.

\section{Pastel de Lagrange o la subversión del «No matarás»}

Los personajes femeninos, minoritarios en los textos largos de Mayorga -o, en todo caso, minoritarios aunque con papeles fundamentales en las obras en las que aparecen-son con mayor frecuencia protagonistas particulares de los contextos de violencia en las piezas breves del autor. Son los casos de Kolakowski y de la mujer, víctimas del horror de la guerra en Concierto fatal de la viuda Kolakowski y en El hombre de oro; o los de las dos hermanas de La piel y el de Margarita de Método Le Brun para la felicidad, mujeres sometidas en los ámbitos doméstico y laboral. Hasta la aparición de Pastel de Lagrange, la mujer violentada en el teatro de Mayorga se ha servido del arte y de la palabra o ha protagonizado un acto de rebeldía para dar fin a la situación de opresión en la que se encuentra: baste recordar a la Bulgákova de Cartas de amor a Stalin, a la Niña de El Cartógrafo o a la Rebeca de Himmelweg. Sin embargo, Toñi toma la decisión de usar las armas como método de resolución a su conflicto: lleva años ahorrando para comprar una pistola con la que matar a su marido pocos días antes de la celebración de sus bodas de plata.

La elección de la violencia explícita por parte del personaje de Toñi plantea, por un lado, el reconocimiento del fracaso de la palabra, la derrota del lenguaje 
como mecanismo de salvación planteado en textos anteriores de Mayorga. Y, por otro, pone al lector/espectador ante la incómoda reflexión de interrogarse sobre la empatía con el victimario, cuestión sobre la que Slavoj Žižek advierte en Seis reflexiones sobre la violencia:

Hay razones para mirar al sesgo el problema de la violencia. Mi premisa subyacente es que hay algo inherentemente desconcertante en una confrontación directa con él: el horror sobrecogedor de los actos violentos y la empatía con las víctimas funcionan sin excepción como un señuelo que nos impide pensar. (2009: 12)

A este respecto, en una entrevista reciente publicada en El Cultural, Mayorga afirmaba lo siguiente: "Situar al espectador en la posición de una víctima me parece moral y políticamente inútil”, explica. "Es más responsable mostrarle al espectador la violencia que puede llevar dentro o su complicidad con la violencia”" (Yuste 2015). Esta idea de la complicidad se plantea en un doble nivel en Pastel de Lagrange: por un lado, en el nivel diegético, pues María José como vendedora y Samuel como intermediario, participan en el proceso de compra-venta de la pistola. Y no solo eso, sino que sobrevuela cierta solidaridad de la violencia entre los personajes: Samuel intenta que María José rebaje el precio de la pistola que Toñi quiere comprar argumentando que lleva muchos años haciendo sacrificios. Ante el inmovilismo de María José, Samuel intenta sensibilizarla apelando a su bonhomía: le ha dicho a Toñi que esas ventas no las hace por dinero, sino por ayudar. De las palabras de Samuel se deriva la cuestión de la legitimidad de la violencia, que estaba ya en La paz perpetua en relación a los límites de la tortura y de la violencia de Estado. A este respecto, resultan muy elocuentes las ideas que expone Hannah Arendt en Sobre la violencia acerca de esta cuestión:

Recurrir a la violencia cuando uno se enfrenta con hechos o condiciones vergonzosos, resulta enormemente tentador por la inmediación e celeridad inherentes a aquélla. Actuar con una velocidad deliberada es algo que va contra la índole de la rabia y la violencia, pero esto no significa que éstas sean irracionales. Por el contrario, en la vida privada, al igual que en la pública, hay situaciones en las que el único remedio apropiado puede ser la auténtica celeridad de un acto violento. [...] el quid está en que bajo ciertas circunstancias -actuando sin argumentación ni palabras y sin consideración a las consecuencias- es el único medio de restablecer el equilibrio de la balanza de la justicia. (2005: 85-86)

Esa idea de justicia es la que subyace en la normalización del acto violento en Pastel de Lagrange. Y es que, si se atiende a las palabras de Samuel, parece que Toñi es un ser manejado, sin autonomía: fue su marido, no ella por voluntad propia, quien decidió que iría a un club de tiro. Como apunta Žižek:

La cuestión está en que las violencias subjetiva y objetiva no pueden percibirse desde el mismo punto de vista, pues la violencia subjetiva se experimenta como tal en contraste con un fondo de nivel cero de violencia. Se ve como una perturbación del estado de cosas normal y pacífico. Sin embargo, la violencia objetiva es precisamente la violencia inherente a este estado de cosas normal. La violencia objetiva es invisible puesto que sostiene la normalidad del nivel cero contra lo 
que percibimos como subjetivamente violento. La violencia sistémica es por tanto algo como la famosa materia oscura de la física, la contraparte de una (en exceso) visible violencia subjetiva puede ser invisible, pero debe tomarse en cuenta si uno quiere aclarar lo que de otra manera parecen ser explosiones «irracionales» de violencia subjetiva. (2009: 10)

En El sacrificio como acto poético, Angélica Liddell afirma que «mediante la angustia se transgreden los límites de la cultura, de la sociedad, de la historia y de la religión» (2014: 110). La determinación de Toñi, que lleva años sacrificándose para poder comprarse una pistola; la necesidad urgente de matar a su marido antes del sábado que celebran la boda de plata; y la solidaridad de María José y Samuel para con su causa -nada habitual en la dramaturgia del autor que se caracteriza por el antagonismo que define a sus personajes- funcionan como elementos perturbadores de las convicciones éticas de ese lector/espectador atento que siempre demanda el teatro de Mayorga.

\section{Bibliografía}

Arendt H., 2005, Sobre la violencia, Madrid, Alianza Editorial.

Aznar Soler M., 2011, «Memoria, metateatro y mentira en Himmelweg, de Juan Mayorga», in: Mayorga J., Himmelweg, Manuel Aznar Soler (ed.), Ciudad Real, Naque, p. 15-112.

Gabrielle J.P., 2000, «Entrevista con Juan Mayorga», ALEC, 25/3, p. 1095-1103.

Gracián B., 1648, Agudeza y arte de ingenio, Huesca.

«Lagrange y la Matemática en la Astronomía», http://www.astromia.com/ biografias/lagrange.htm [Consulta: 22/11/2016].

Liddell A., 2014, El sacrificio como acto poético, Madrid, Continta Me Tienes.

Mayorga J., 2010, «Elipses de Benjamin», Constelaciones. Revista de Teoría Crítica, 2, p. 372-374.

Molanes Rial M., 2012, «Entrevista a Juan Mayorga», Anagnórisis. Revista de investigación teatral, 6, p. 193-206.

Molanes Rial M., 2015, “"El arte de la entrevista”, con Juan Mayorga», Ínsula. Revista de Letras y ciencias Humanas, 823-824, p. 17-19.

Rojo A., 1999, «El jardín de los mundos que se ramifican: Borges y la mecánica cuántica», Ciberletras: Revista de crítica literaria y de cultura, 1, p. 59-67.

Surbezy A., en prensa, «¿Dispositivos cuánticos? De la física cuántica a la Escuela de los Dispositivos en Del lado oeste del Golden Gate de Pablo Iglesias Simón», in: Teatros y escenas del siglo XXI, Vigo, Editorial Academia del Hispanismo.

Yuste J., 2015, «La mochila de Juan Mayorga», El Cultural, http://www.elcultural. com/noticias/escenarios/La-mochila-de-Juan-Mayorga/8709 [Consulta: 22/11/2016].

Žižek S., 2009, Sobre la violencia: seis reflexiones marginales, Buenos Aires, Paidós. 